\title{
A INCLUSÃO ESCOLAR DO ALUNO COM PARALISIA CEREBRAL: A PERCEPÇÃO DOS PROFESSORES DO ENSINO FUNDAMENTAL
}

\author{
THE SCHOOL INCLUSION OF THE STUDENT WITH \\ CEREBRALPALSY: THE PERCEPTION OF TEACHERS OF \\ ELEMENTARY SCHOOL
}

\section{LA INCLUSIÓN ESCOLAR DEL ALUMNO CON PARÁLISIS CEREBRAL: LA PERCEPCIÓN DE LOS PROFESORES DE LA EDUCACIÓN FUNDAMENTAL}

Neide Maria Fernandes Rodrigues de Sousa ${ }^{1}$

https://orcid.org/0000-0002-9129-0319

Andresa da Luz Ramos ${ }^{2}$

https://orcid.org/0000-0001-6544-0953

Francisco Pereira de Oliveira ${ }^{3}$

https://orcid.org/0000-0003-1327-8362

Norma Cristina Vieira ${ }^{4}$

https://orcid.org/0000-0003-2618-3346

\footnotetext{
${ }^{1}$ Universidade Federal do Pará, Belém, Pará, Brasil. E-mail: nmfrs@ufpa.br.

${ }^{2}$ Universidade Federal do Pará, Belém, Pará, Brasil. E-mail: andresa.ramos17@ gmail.com.

${ }^{3}$ Universidade Federal do Pará, Belém, Pará, Brasil. E-mail: foliveiranono@ yahoo.com.br.

${ }^{4}$ Universidade Federal do Pará, Belém, Pará, Brasil. E-mail: normacosta@ufpa.br.
}

\section{Resumo}

A presente pesquisa visa compreender a percepção de professores do ensino fundamental acerca da inclusão escolar do aluno com paralisia cerebral. Participaram da pesquisa seis professores do ensino fundamental de uma turma do $8^{\circ}$ ano que tinha uma aluna com paralisia cerebral. O levantamento foi realizado por meio de entrevista semiestruturada. Nos resultados, os participantes indicaram desconhecer o Projeto Político Pedagógico/currículo e sua articulação com práticas inclusivas. Além disso, eles têm pouca compreensão das características da paralisia cerebral, assim como apresentam dificuldades no planejamento e na prática pedagógica inclusiva para alunos público-alvo da educação especial, 
principalmente na aplicação de metodologias; eles implementam poucas flexibilizações curriculares, justificando-as em função do reduzido preparo profissional para atuar com a aluna com paralisia cerebral e a falta de material adequado. Conclui-se que, apesar do avanço no aspecto legal da educação inclusiva, há um conjunto de barreiras para que se efetive uma política educacional inclusiva de qualidade em turmas com portadores de paralisia cerebral, o que dificulta o processo de desenvolvimento e aprendizagem da referida aluna.

Palavras-chave: Inclusão Educacional. Aluno com Paralisia Cerebral. Práticas Pedagógicas.

\begin{abstract}
This research aims to understand the perception of Elementary School teachers about the school inclusion of students with cerebral palsy. Six elementary school teachers from an 8th grade class who had a student with cerebral palsy participated in the research. The survey was conducted through semi-structured interviews. In the results, the participants indicated that they were unaware of the Political Pedagogical Project/curriculum and its articulation with inclusive practices, in addition, they have little understanding of the characteristics of cerebral palsy, as well as presenting difficulties in planning and inclusive pedagogical practice for students especially in the application of methodologies; they implement few curricular flexibilities, justifying them due to the reduced professional preparation to work with the student with cerebral palsy and the lack of adequate material. It is concluded that, despite the advancement in the legal aspect of inclusive education, there are a number of barriers for the implementation of an inclusive educational quality policy in classes with students with cerebral palsy, which hinders the development and learning process of that student.
\end{abstract}

Keywords: Educational Inclusion. Students with Cerebral Palsy. Pedagogical Practices.

\title{
Resumen
}

Esta investigación tiene como objetivo comprender la percepción de los docentes de educación fundamental sobre la inclusión escolar de estudiantes con parálisis cerebral. En la investigación participaron seis maestros de educación fundamental de una clase de octavo grado que tenían una alumna con parálisis cerebral. La encuesta se realizó mediante entrevistas semiestructuradas. En los resultados, los participantes señalaron que desconocían el Proyecto Político Pedagógico/currículo y su articulación con prácticas inclusivas. También, tienen poca comprensión de las características de la parálisis cerebral, además de presentar dificultades en la planificación y práctica pedagógica inclusiva para los estudiantes, especialmente en la aplicación de metodologías; implementan pocas flexibilidades curriculares, justificándolas ante la reducida preparación profesional para trabajar con el alumno con parálisis cerebral y la falta de material adecuado. Se concluye que, a pesar del avance en el aspecto legal de la educación inclusiva, existe una serie de barreras para la implementación de una política de calidad educativa inclusiva en las clases con alumnos con parálisis cerebral, lo que dificulta el desarrollo y proceso de aprendizaje de la alumna en cuestión.

Palabras clave: Inclusión Educativa. Alumnos con Parálisis Cerebral. Práctica Pedagógica. 


\section{Introdução}

Nas últimas décadas, a educação inclusiva se tornou um campo polêmico de discussão, assumindo status privilegiado nos discursos acadêmicos e sociais. Enquanto princípio no contexto escolar, deve ser evidenciado em valores como igualdade, diferenças e democratização, portanto se concentra nas singularidades do sujeito desencadeadas por diferentes situações, que podem ser desde a condição de deficiência até as peculiaridades culturais e sociais (CARVALHO, 2013).

Na perspectiva da educação especial, a inclusão educacional vai além do acesso à escola, pois é preciso oferecer educação de boa qualidade e garantir condições de permanência e de aprendizagem para todos. A inclusão de alunos público-alvo da educação especial (PAEE) na rede de ensino envolve um repensar das ações escolares com modificações, principalmente, nos valores e na cultura da escola, na formação de professores, nos currículos e no trabalho pedagógico. Logo, no atendimento educacional de crianças e jovens, público-alvo da educação especial, as possibilidades de transformações no contexto escolar exigem desafios no cotidiano, tornando-se um ponto de tensão na realidade educacional (MARCHESI, 2004; RODRIGUES, 2001).

O indivíduo com paralisia cerebral (PC) faz parte do grupo PAEE. Nessa direção, o ambiente escolar para o aluno com PC deve ser o mais diversificado possível, bem como apresentar um conjunto de flexibilizações curriculares e o uso de tecnologias assistivas (TAs). Essas ações favorecem a aprendizagem, o desenvolvimento das potencialidades e o exercício da cidadania (MELO; MARTINS, 2007; SILVA; SANTOS; RIBAS, 2011).

Com base no exposto, questiona-se: como ocorre a inclusão escolar do aluno com PC em uma escola pública? Para responder à questão, a pesquisa tem como objetivo geral compreender a percepção de professores do ensino fundamental acerca da inclusão escolar do aluno com paralisia cerebral.

\section{A educação inclusiva e o aluno com paralisia cerebral}

A inclusão objetiva o desenvolvimento de competências e a afirmação da identidade dos indivíduos, levando em conta suas singularidades e potencialidades. O modelo de educação inclusiva nos documentos oficiais destaca o compromisso com a democratização e a 
equidade, a universalização, o acesso e a permanência, com o reconhecimento do direito à educação em uma formação plural (OMOTE, 2004; MENDES, 2001).

No Brasil, a inclusão educacional ocorreu a partir da década de 1990, com a construção de um conjunto de normativas oficiais para subsidiar a organização dos sistemas de ensino e promover a expansão do acesso e permanência de estudantes PAEE, como, por exemplo, a Política Nacional de Educação Especial na Perspectiva da Educação Inclusiva (PNEEPEI) em 2008; o Plano Nacional de Educação (PNE), em 2014, o Estatuto da Pessoa com Deficiência, em 2015, e a Base Nacional Comum Curricular (BNCC), de 2017.

O PNEEPEI de 2008 orienta os sistemas de ensino a oferecer respostas às necessidades educacionais, sugerindo, entre outros, formação de professores, acessibilidade (urbanística, arquitetônica, nos mobiliários e equipamentos, nos transportes, na comunicação e informação) e articulação intersetorial das políticas públicas. O PNE 2014-2024 (Lei n ${ }^{\circ}$ 13.005/2014), na meta 4, direciona-se para a Educação Especial/Inclusiva. O Estatuto da Pessoa com Deficiência (Lei $\left.\mathrm{n}^{\circ} 13.146 / 2015\right)$ foi um avanço para garantir os direitos e a proteção da dignidade da pessoa com deficiência. Outro documento normatizador, a BNCC de 2017, reconhece as necessidades dos alunos com deficiência, preconiza a equidade e a superação das desigualdades, com orientação para a diferenciação curricular e as práticas pedagógicas inclusivas (BRASIL, 2008, 2014, 2015, 2017).

A escola inclusiva exige uma série de modificações na organização estrutural e curricular para reduzir pressões excludentes e favorecer a aprendizagem de todos coletivamente. Entre elas destacam-se: a cultura e os valores da escola, o projeto pedagógico, as flexibilizações curriculares, a estrutura física, o uso de materiais e recursos adaptados, as capacitações e formações continuadas dos professores, as relações sociais no contexto da escola, além do envolvimento de todos os atores do contexto escolar (BOOTH; AINSCOW, 2002; MARCHESI, 2004; MANTOAN, 2003, 2008; RODRIGUES, 2006).

O currículo inclusivo, explicitado no projeto pedagógico da escola, caracteriza-se por ser aberto, dinâmico, flexível e que responda à diversidade. Ele deve ser operacionalizado de tal forma que atenda a todos os estudantes. Nesse sentido, a flexibilidade curricular ou diferenciação curricular, compreendida a partir dos níveis político, organizacional e pedagógico, está relacionada com as práticas curriculares e os dispositivos didáticopedagógicos (BLANCO, 2004; PACHECO, 2008). 
A formação docente é outro ponto crítico no debate sobre a política educacional inclusiva. Estudos como os de Cruz e Glat (2016), Glat e Pletsch (2011) e Vitalino (2010) enfatizam a importância de formação dos professores comprometidos com o contexto atual e com as políticas implementadas. Na relação formação dos professores e educação especial, observam-se debates generalistas sobre a inclusão, abordando de forma superficial as questões das diferenças específicas do PAEE. Araújo et al. (2010), em uma pesquisa, afirmam que a formação dos professores na área da inclusão e no atendimento de deficientes não aprofunda questões específicas da inclusão das várias deficiências. Assim, é preciso pensar a formação de professores direcionada à realidade escolar e em consonância com a política educacional.

\subsection{O aluno com paralisia cerebral, as flexibilizações curriculares individuais e o uso de tecnologia assistiva}

A PC é uma condição complexa de distúrbios da motricidade voluntária, uma alteração do controle motor secundário decorrente de uma lesão encefálica causada por fatores pré, peri e pós-natais, com desordens motoras, sensoriais, perceptivas, cognitivas e de comunicação. A pessoa com esse distúrbio pode ter alterações no desenvolvimento global, em específico no sistema motor e na comunicação, com limitações na sua funcionalidade, necessitando, no processo de escolarização, de demandas específicas para acessar o conteúdo curricular (BASIL, 2004; BRASIL, 2013; GONZÁLEZ, 2007).

$\mathrm{Na}$ inclusão escolar de alunos com PC, situações específicas podem dificultar ou facilitar o desenvolvimento e a aprendizagem dos alunos. A acessibilidade (de comunicação, de recursos e de espaços), o ensino-aprendizagem e as interações sociais são algumas dimensões que, se não forem oferecidas com qualidade, podem impossibilitar ou dificultar a aprendizagem dos conteúdos escolares, assim como a participação dos alunos em uma vida social mais ampla (FACHINETTI; GONÇALVES; LOURENÇO, 2017; SANCHEZ; ALMEIDA; GONÇALVES, 2017).

As flexibilizações ou diferenciações curriculares individuais são desenhos organizacionais em que se oferecem ao aluno diferentes modalidades de formação ou um currículo alternativo. Ademais, pressupõem a ideia de que todos aprendem juntos, a partir de uma base curricular comum com a igualdade de oportunidades, considerando a realidade individual de cada estudante. Essas diferenciações abrangem a reorganização do ensino- 
aprendizagem, cumprindo os conteúdos básicos de modo flexível, favorecendo uma interpretação de hierarquização do acesso aos conhecimentos a partir das diferenças individuais, com respeito ao ritmo do aluno, aos estilos de aprendizagem e às dificuldades de alguns. Visam também ao estímulo das capacidades, interesses e motivações dos alunos e vêm auxiliar o aluno com PC para que ele tenha sucesso na aprendizagem e saltos qualitativos no desenvolvimento (DIAS, 2011; RIBEIRO; BAUMEL, 2003; PLETSCH; SOUZA; ORLEANS, 2017; ROLDÃO 2003).

A tecnologia assistiva caracteriza-se por produtos, recursos, metodologias, estratégias, práticas e serviços que auxiliam ou ampliam habilidades funcionais de pessoas com deficiência, gerando autonomia e inclusão. Para o aluno com PC, a TA envolve a utilização de sistemas suplementares e alternativos para a comunicação, as adaptações no material pedagógico (como o uso de engrossadores, de tesouras adaptadas com ligas ou tubos de borracha, de mouses e teclados adaptados, do caderno eletrônico etc.), a organização do mobiliário e o posicionamento do aluno, sendo de grande valia para o apoio na rotina escolar, nas atividades de vida diária e na autonomia. No contexto escolar, quando se trata do uso de TA, é necessário conhecer o estudante usuário do recurso (a história, as características psicomotoras e comunicacionais, o ambiente social e as dificuldades apresentadas), assim também organizar situações desafiadoras para que ele possa construir novos conhecimentos (BERSCH, 2017, 2008; BERSCH; TONOLLI, 2006; TELES; SANTOS, 2012).

\section{0 cenário metodológico}

Foi adotada uma abordagem qualitativa, do tipo estudo de caso. Nessa modalidade de pesquisa se busca a compreensão do fenômeno social, interpretando-o segundo o ponto de vista dos próprios sujeitos que participam da ação, sem se prender a representação de números, generalizações estatísticas e relações lineares de causa e efeito. Já o estudo de caso tem como foco um caso particular, considerado representativo de um conjunto de casos análogos por ele significativamente representados, permitindo o conhecimento aprofundado de uma realidade delimitada (GUERRA, 2014; GIL, 2019; SEVERINO, 2017). 


\subsection{Participantes}

Participaram da pesquisa seis professores de uma turma de $8^{\circ}$ ano do ensino fundamental, sendo quatro do sexo feminino e dois do sexo masculino. O tempo de atuação dos docentes varia entre 3 e 18 anos, todos possuem graduação e um é pós-graduado em nível de especialização.

Apesar de a aluna com PC não participar da pesquisa, é pertinente fazer uma caracterização superficial dela a partir de observações informais (na sala de aula, no pátio e na copa da escola) e entrevista com a professora da sala de AEE, o que auxilia no tratamento e na interpretação dos dados.

A aluna tem 19 anos de idade, é portadora PC do tipo espástica, tem dificuldades na emissão das palavras, com fala pouco compreensível, movimentos corporais vagarosos e postura assimétrica; comunica-se muito com gestos; faz atendimento especializado, acompanhamento com fonoaudiólogo e pratica aeróbica no período da manhã. Ela está nessa escola desde 2014, cursa o $8^{\circ}$ ano do ensino fundamental no período da tarde, relaciona-se bem com os funcionários da escola, principalmente os da copa, tem maior quantidade de interações com a cuidadora e poucas frequências interacionais com os colegas e professores da turma. A aluna apresenta distorção idade-série.

Nessa breve descrição da aluna com PC, destaca-se a sua defasagem escolar, situação que vai de encontro dos resultados do estudo de Santos e Mendes (2019) sobre distorção idade-série de alunos PAEE no estado de São Paulo. Os autores indicaram uma defasagem escolar no período de 2008 a 2014, sem diminuição proporcional ao longo dos anos, ocorrendo de forma majoritária nos anos finais dos ensinos fundamental e médio; além disso, sugeriram a avaliação da política inclusiva e dos apoios oferecidos aos estudantes PAEE.

\subsection{Lócus}

O levantamento foi realizado em uma escola pública na cidade de Tracuateua, no estado do Pará, na turma do $8^{\circ}$ ano que tem uma aluna com PC. A instituição atualmente tem 456 alunos matriculados, distribuídos entre educação infantil e ensino fundamental. Desse total de estudantes, cinco apresentam PC. A escola dispõe de nove salas de aula, sala de leitura, sala de Atendimento Educacional Especializado (AEE), uma rampa na entrada que dá 
acesso ao espaço escolar e um banheiro denominado especial (que não possui, entretanto, adaptação).

\subsection{Procedimentos de levantamento e análise}

Para o levantamento de dados, utilizaram-se a entrevista semiestruturada com um roteiro preestabelecido e o Termo de Consentimento Livre e Esclarecido (TCLE). As entrevistas tiveram duração média de 60 minutos para cada participante. Na organização e interpretação dos dados, aplicou-se a análise de conteúdo proposta por Bardin (2011), estruturada em três polos: pré-análise, exploração do material e tratamento dos resultados inferência e interpretação. Na pré-análise, realizou-se a organização das entrevistas, com a transcrição e a leitura flutuante. Na exploração do material, ocorreu a codificação, com o recorte das narrativas dos professores, a classificação e agregação das informações em unidades de sentido, as quais foram agrupadas por similaridade de conteúdo. No tratamento dos resultados, identificaram-se as informações explícitas e latentes contidas no levantamento, bem como foram feitas a síntese dos resultados e as inferências e interpretações.

\section{Resultados e discussões}

$\mathrm{Na}$ intenção de atingir o objetivo da pesquisa, que é compreender como os professores percebem a inclusão escolar de alunos com paralisia cerebral no ensino fundamental, realizouse o tratamento das entrevistas. Da análise dos dados emergiram as seguintes categorias temáticas: 1. o projeto político pedagógico (PPC) e o currículo escolar; 2. o conhecimento sobre paralisia cerebral; 3. a formação docente; 4. o trabalho pedagógico e a flexibilização curricular.

\subsection{O PPC e o currículo escolar}

Aborda-se neste tópico a questão da entrevista sobre o conhecimento do currículo inclusivo expresso no PPC e este como orientador do planejamento e das práticas pedagógicas inclusivas. Dos seis professores, quatro afirmaram que o PPC e o currículo da escola não orientam nem auxiliam o planejamento e as práticas pedagógicas inclusivas, não havendo relação com a prática direcionada aos alunos alvo da educação especial. Um participante 
informou desconhecer o PPC e outro afirmou não ter tido discussão sobre o mesmo, conforme as narrativas abaixo:

Na teoria, o PPC atende à educação inclusiva, mas, na prática, não, fica no discurso (Participante 3).

Não foi discutido no PPC. Quando nos reunimos no planejamento da escola para discutir os assuntos a serem trabalhados, falamos apenas de conteúdos a serem repassados para os alunos em sala de forma geral, não é falado nada sobre educação especial (Participante 1).

As narrativas dos professores 1 e 3 revelam que o PPC não é um documento dinâmico que orienta a prática pedagógica, mas, sim, um documento oficial sem relação com o cotidiano do trabalho docente, não auxiliando, portanto, as práticas inclusivas exitosas. Entende-se que o currículo da escola, materializado no PPC, não é neutro nem estático, refletindo valores e um tipo de racionalidade educativa, além de modos de práticas pedagógicas. Assim, se, para o grupo dos professores entrevistados, o PPC da escola não é um documento orientador das ações pedagógicas, pode-se deduzir que a falta de um aporte documental que embase o trabalho docente dificulta as práticas inclusivas exitosas no cotidiano da sala de aula. Logo, questiona-se se esse modelo de política curricular se materializa com qualidade no cotidiano das escolas em uma perspectiva inclusiva.

As políticas curriculares por meio da elaboração de parâmetros e diretrizes desenvolvem a organização curricular a partir de um modelo prescritivo com pressupostos específicos, um tipo de racionalidade, de crenças e de valores, buscando intervir no trabalho pedagógico e nas práticas educativas. Em contrapartida, as teorias curriculares buscam ir além da questão prescritiva, visando à compreensão do sentido e significado, em particular as teorias críticas e pós-críticas. Nessa direção, as ações educativas na escola envolvem um questionar constante das práticas políticas e administrativas, não sendo compreendidas como algo estático e pronto, ou seja, um processo dinâmico e construído no e pelo contexto social, com possibilidades de ressignificações e orientações (MESQUITA, 2010; SACRISTÁN, 2000). 


\subsection{A compreensão do aluno com paralisia cerebral}

Nesta subseção, trata-se da questão sobre a visão dos professores acerca das informações sobre paralisia cerebral e a aluna com PC. De modo geral, as narrativas dos participantes remeteram para as seguintes temáticas: alunos com problemas relacionados a distúrbios de comunicação e motor, precisando de uma aprendizagem individual; aluna com dificuldade de aprendizagem e dificuldade de assimilar o conhecimento e barreiras devido a uma condição especial; não tem conhecimento sobre PC.

A maioria dos participantes, quando se reporta à aluna com PC, enfatiza as dificuldades motoras e de comunicação, bem como destaca que esses problemas físicos podem resultar em "barreiras" para que se efetive o processo de inclusão escolar. Além dos aspectos mencionados, notou-se nas falas dos participantes a informação de que a aluna com PC tem dificuldade de assimilar o conhecimento e a indicação de uma aprendizagem individualizada para ela. Observa-se nessas narrativas o foco no déficit, e não nas possibilidades de aprendizagem da aluna. Não se constatou, nas falas dos participantes, a ideia de que, apesar das dificuldades, sejam elas motoras, de comunicação e de aprendizagem, devem-se explorar as potencialidades da aluna com PC com vistas a proporcionar o seu desenvolvimento e aprendizagem. Segundo Basil (2004), as necessidades especiais desses alunos devem ser vistas mais como um desafio do que como obstáculo. Para o autor, a primeira percepção dos educadores sobre um aluno com PC é a de que têm diante de si um estudante a quem devem ajudar, assim como todos os outros, aproveitando e explorando suas potencialidades e propiciando o seu desenvolvimento e aprendizagem.

A falta de informações de professores sobre os alunos com PC pode levá-los a generalizar os comprometimentos neuropsicomotores para as questões cognitivas. Tal visão facilita situações de preconceito aos alunos com PC. De acordo com Franco e Guerra (2015), na identificação da paralisia cerebral, os professores de forma equivocada atribuem deficiência cognitiva à criança com paralisia cerebral que tem graves comprometimentos motor e de fala. 


\subsection{A formação docente}

Sobre a formação docente, duas questões foram consideradas na entrevista: formação em educação inclusivaleducação especial e formação direcionada para o ensinoaprendizagem de alunos com paralisia cerebral.

Referente à formação na área de educação inclusiva/educação especial, todos os professores afirmaram terem participado. Nas narrativas sobre a participação em formações ou capacitações direcionadas ao ensino-aprendizagem de alunos com PC, cinco professores disseram não ter participado de formação nessa área; no entanto um professor afirmou que participou de forma superficial de uma formação na área de paralisia cerebral. Os excertos a seguir trazem as falas dos professores:

Tive formação na área de inclusão, mas não especificamente para trabalhar com paralisia cerebral (Participante 3).

Já participei. Sempre há formações para os professores, mas é discutido de forma geral, não há aprofundamento. Tive uma formação de forma superficial na área de paralisia cerebral, apenas uma pequena discussão. Sabe, falta mais, deveria ter sido mais aprofundado (Participante 4).

Os dados indicam que, ainda hoje, uma das barreiras para práticas inclusivas exitosas é a carência de formações ou capacitações dos professores para atuar no contexto da sala de aula, sendo significativo sugerir que as políticas públicas municipal precisam melhorar a qualificação dos professores na área da educação especial. Essa formação está prevista no Plano Nacional de Educação/Lei n ${ }^{\circ}$ 10.172/2014, que elenca objetivos relacionados com a formação de professores para atuar na educação especial. Um dos requisitos para que a inclusão escolar ocorra de fato é, portanto, o aperfeiçoamento constante dos profissionais da Educação.

A formação continuada de professores é essencial para que eles possam ter domínio instrumental e conceitual que os auxiliem na evolução de suas práticas pedagógicas; logo, os professores devem possuir conhecimento e habilidades necessárias para adaptar o currículo e a metodologia, de ensino de forma a atender às necessidades individuais do educando com deficiência (GLAT; PLETSH, 2011; GOMES; BARBOSA, 2006; MARCHESI, 2004).

Nesse sentido, Franco e Guerra (2015) sugerem algumas ações referentes à formação e à atuação docente em turmas com alunos com PC: um domínio conceitual superficial sobre o 
transtorno e as possibilidades de aprendizagem, articulando tais conhecimentos com a prática; a formação em serviço, considerando as dificuldades de professores; a possibilidade de construção de instrumentos que facilitam o ensino-aprendizagem; e a intersetorialidade com a área da saúde, em que os profissionais da saúde auxiliariam na formação.

Assim, a formação continuada e o desenvolvimento profissional são essenciais para a educação inclusiva, porém essas só influenciarão positivamente no trabalho docente quando resultarem num repensar dos valores e atitudes dos docentes diante da própria atuação profissional. E isso envolve um refletir sobre cultura, valores e as diferenças na escola, além dos desafios do papel docente no cotidiano escolar, haja vista que, se os professores não julgarem ser de sua responsabilidade educar toda e qualquer pessoa, a formação terá pouco impacto na prática pedagógica.

\subsection{O trabalho pedagógico}

Sobre o trabalho pedagógico, as questões da entrevista se direcionaram para as temáticas: o planejamento, a prática pedagógica e a diferenciação curricular individual; o processo de ensino-aprendizagem; a sala de recursos multifuncional; e a avaliação escolar.

A respeito do planejamento, as narrativas dos participantes incluíram planejar as atividades fazendo modificações no conteúdo e nos procedimentos direcionadas ao aluno com PC. Um participante informou que planeja as aulas para a turma, exceto para o aluno com PC, que fica sob a responsabilidade da cuidadora. E sobre a prática pedagógica no cotidiano escolar, as falas expressaram a palavra obstáculos relacionada como aluno com PC, como: não saber lidar com o aluno devido à falta de conhecimento na área de educação especial; material inadequado; falta de metodologias específicas; dificuldade na comunicação com o aluno e pouco tempo para trabalhar com o aluno; falta de capacitação na área de educação especial e o pouco apoio recebido.

Por conseguinte, todos os participantes indicaram ter dificuldades no planejamento e prática pedagógica do aluno com PC. As narrativas dos professores expressam os obstáculos a uma prática docente inclusiva:

Planejo as minhas aulas para os demais alunos. Para a aluna com PC, a cuidadora fica responsável em trazer atividades para ela, mas eu sempre estou dando o apoio (Participante 3). 
A inclusão escolar do aluno com paralisia cerebral: a percepção dos professores do ensino fundamental

A dificuldade está em dedicar atenção a esse aluno, não saber lidar com ele, devido à falta de conhecimento, e não ter material adequado para trabalhar (Participante 1).

A falta de conhecimento e de metodologias específicas é a principal dificuldade em trabalhar com o aluno (Participante 2).

A dificuldade é como devo me expressar com ele, a comunicação é difícil. A falta de material adequado é outro fator que dificulta (Participante 6)

Chama a atenção nos relatos dos professores que as dificuldades estão diretamente relacionadas com a formação docente. Entende-se que a efetivação de práticas educacionais inclusivas requer, necessariamente, desses profissionais conhecimentos para adaptar o currículo às necessidades específicas do aluno. Essas capacitações devem se direcionar não só para estratégias metodológicas, mas também para questões atitudinais.

No que concerne à diferenciação curricular individual, os participantes afirmaram fazer as adequações, assim discriminadas: simplificar o conteúdo e preparar atividades diferenciadas para a aluna, como desenhos e imagens, e, redobrar a atenção, preparando atividades diferenciadas. Na narrativa, a participante expressa como fez a diferenciação curricular:

Faço adaptações no conteúdo para a aluna com PC; é algo que cada professor tem que fazer individualmente, pois não percebi a inclusão no planejamento da escola voltada para a aluna com paralisia cerebral nem para outras deficiências (Participante 6).

Para Almeida (2012), na diferenciação pedagógica, a ênfase deve ser dada aos estilos de aprendizagem, tendo como referências a identificação e a valorização das competências dos alunos. Para tanto, os professores devem usar metodologias materiais e recursos diversos. Heredero (2010), utilizando o termo adaptações curriculares, afirma que essas devem ocorrer no planejamento escolar e pedagógico, bem como nas ações educacionais direcionadas ao atendimento das necessidades dos alunos público-alvo da educação especial, sendo relativas e mutantes. 
No âmbito da inclusão escolar para as práticas pedagógicas com qualidade, em algumas situações é imprescindível fazer a diferenciação curricular individual: um currículo adaptado individualmente, estabelecendo o que ele deverá aprender, em que seguimento, como se deve ensinar e como será feita a avaliação (BLANCO, 2004; MARCHESI, 2004).

A efetivação de práticas educacionais inclusivas direcionadas aos alunos com PC requer conhecimentos de diferentes áreas, como: entendimento sobre o transtorno; como diferenciar o currículo e as necessidades específicas do aluno; o uso de novas práticas que facilitem o processo de aprendizagem do aluno e informações sobre acessibilidade.

A respeito da aprendizagem e da avaliação da aluna com PC, os professores assinalaram como pontos positivos: a socialização com professores e demais alunos, boa assimilação e atenção. E como pontos negativos indicaram: a aluna não ser alfabetizada, dificuldade na escrita e pouco estímulo familiar. Referente à avaliação da aluna com PC, todos os professores afirmaram aplicar provas e trabalhos e informaram que a forma de avaliar é diferenciada dos demais alunos, levando-se em consideração mais a interação social, a participação nas atividades, o comportamento e a atenção da educanda.

Dois aspectos expressos pelos participantes sobre a aprendizagem e avaliação da aluna com PC chamaram a atenção: a ênfase no aspecto social em detrimento da dimensão cognitiva e o fato de a aluna não ser alfabetizada. A partir das informações apresentadas pelos professores, é possível questionar: por que limitar um aspecto essencial da escolarização da aluna, que é a aprendizagem/avaliação dos conteúdos do currículo? Considerando tais situações, é sugestivo pensar que há limitação no direito à aprendizagem de conhecimentos da aluna com PC. Adiante, algumas falas retratam esses pontos.

A aprendizagem é positiva, pois interage com os professores e com os demais alunos. Negativo: não é alfabetizada (Participante 1)

De positivo não tiveram muitos, pois não é alfabetizada. O negativo é que não é alfabetizada porque não se trabalha em cima disso, nem a escola, nem a família; querem apenas passar a aluna de ano, levando-se mais em conta apenas a presença da aluna na escola (Participante 2).

Avalio a aluna a partir da interação, participação, roda de conversa (Participante 4). 
Minha avaliação é através de provas e trabalhos, levando mais em conta o comportamento e atenção da aluna em sala (Participante 6).

Avalio de forma diferenciada de acordo com o que é proposto para a aluna. Metade da nota é a partir da participação e interação em sala e a outra metade é através de provas (Participante 3).

Para Marques, Oliveira e Santos (1998), a proposta de educação inclusiva, para muitos docentes, tem como importância apenas a possibilidade de interação social dos alunos com deficiência, visando muito mais ao "bem-estar" social desses alunos, desconsiderando as possibilidades de um real desenvolvimento cognitivo. No caso do aluno com PC, é preciso ir além da visão do déficit e pensar em possibilidades reais de aprendizagem. Leite e Prado (2004) enfatizam que, para avaliar o potencial cognitivo de alunos com PC, os instrumentos utilizados devem estar relacionados com as metas estabelecidas na flexibilização curricular. Para os autores, as escolas precisam de instrumentos adequados de avaliação.

Sobre o serviço na sala de Atendimento Educacional Especializado, cinco participantes afirmaram não receberem qualquer tipo de orientação ou apoio que os auxiliem no trabalho com a aluna com PC. Um participante afirmou receber orientações da professora da sala do AEE.

Embora o docente seja o principal mediador na construção do processo de ensinoaprendizagem do aluno, Basil (2004) deixa claro que, em função da complexidade que um aluno com PC pode apresentar, a sua educação sempre terá de ser um trabalho em equipe. Assim, para uma prática de qualidade na inclusão escolar, é necessário a inter-relação entre classe e sala de AEE, em prol do desenvolvimento e aprendizagem, com um conjunto de ações como o levantamento das necessidades dos alunos, a diferenciação curricular individual, a orientação aos professores e o uso de TA (do tipo comunicação alternativa, engrossadores de caneta, lápis, entre outros). Essas estratégias podem impulsionar o desenvolvimento e a aprendizagem do aluno com PC (BERSCH, 2008; PELOSI, 2008; ROCHA; DELIBERATO, 2012). 


\section{Considerações finais}

Esta pesquisa propôs investigar a percepção dos professores ante a inclusão escolar do aluno com PC. Os resultados indicaram que os participantes não percebem o PPC e o currículo como orientadores do seu trabalho. Além disso, eles têm muitas dificuldades no planejamento e nas práticas pedagógicas inclusivas, nas flexibilizações curriculares, seja no contexto da turma, seja no individual. A maioria dos professores não consegue trabalhar de forma efetiva com a aluna com PC. Eles sinalizaram não possuir um preparo profissional adequado, bem como indicaram não ser suficiente frequentar formações do modo como elas são atualmente, desejando participar de formações mais consistentes e que realmente os ajudem na sua prática pedagógica cotidiana.

Logo, é fundamental questionar a qualidade das políticas educacionais inclusivas e, consequentemente, a formação e atuação de docentes da escola regular para que haja uma inclusão escolar bem-sucedida. A capacitação e/ou a formação continuada de professores assumem grande importância para práticas inclusivas com qualidade, principalmente diante de uma realidade como as das nossas instituições de ensino, que, em sua maioria, desconsideram os conhecimentos produzidos na educação especial.

Sugere-se que a deficiência seja abordada de forma realista, atualizada e historicamente contextualizada. Os professores precisam de um espaço para dialogar e refletir sobre a questão do desenvolvimento profissional. Eles precisam dar continuidade à sua formação, com vistas a refletir sobre a prática pedagógica na perspectiva da educação especial/educação inclusiva e redimensioná-la no seu cotidiano.

Outros pontos destacados nos resultados foram: a carência de informação sobre paralisia cerebral; a não utilização de metodologias específicas e de adequações curriculares individuais; e a falta de material adequado. Essas questões culminam em barreiras para que se efetivem a inclusão escolar, o desenvolvimento e a aprendizagem do aluno com PC. Nesse sentido, é possível inferir que ações pouco eficazes no plano pedagógico direcionadas às necessidades educacionais do aluno com PC podem resultar em situações negativas, como a reduzida aprendizagem do aluno, com repercussões desfavoráveis ao processo pedagógico e psicológico desse aluno, bem como ao próprio bem-estar emocional do docente.

Propõe-se que o PPC seja objeto de reflexão e venha subsidiar de fato o trabalho docente, assim como um dos caminhos para transpor as dificuldades apresentadas pelos 
professores em trabalhar com o aluno com PC seria a escola trabalhar a intersetorialidade de políticas públicas, organizando parcerias com instituições especializadas e profissionais da saúde, como o terapeuta ocupacional, colaborando, assim, com professores e visando a dar suporte à prática pedagógica do professor junto ao aluno com PC.

Por fim, é preciso refletir sobre a possibilidade de práticas pedagógicas apoiadas na ideia do professor pesquisador, com espaços de reflexão sobre a própria ação na realidade escolar.

\section{Referências}

ALMEIDA, P. M. Aprender com a Expressão Dramática! Relatório de Estágio para obtenção do grau de Mestre, Departamento de Ciências da Educação, Universidade dos Açores, Portugal. 2012.

ARAUJO, M. V. et al. Formação de professores e inclusão escolar de pessoas com deficiência: análise de resumos de artigos na base SciELO. Rev. Psicopedag., São Paulo, v. 27, n. 84, p. 405-416, 2010. Disponível em: http://pepsic.bvsalud.org/scielo. php?. Acesso em: 10 abr.2019.

BARDIN, L. Análise de Conteúdo. Lisboa, Portugal; Edições 70, LDA, 2011. 229 p.

BASIL, C. Os alunos com paralisia cerebral e outras alterações motoras: Desenvolvimento e Educação. In: COLL, C. et al. (org.). Desenvolvimento psicológico e educação: necessidades educativas especiais e aprendizagem escolar. 2. ed. Porto Alegre: Artmed, 2004. p. 215-233.

BERSCH, R. Tecnologia Assistiva e atendimento educacional especializado: conceitos que apoiam a inclusão escolar de alunos com deficiência. In: MANTOAN, M. T. E. (org.). O desafio das diferenças nas Escolas. Petrópolis: Vozes, 2008. p. 131- 137.

BLANCO, R. A atenção à diversidade na sala de aula e as adaptações do currículo. In: COLL, C. et al. (org.). Desenvolvimento psicológico e educação: necessidades educativas especiais e aprendizagem escolar. 2. ed. Porto Alegre: Artmed, 2004. p. 290-308.

BRASIL. Ministério da Educação. Base Nacional Comum Curricular. Brasília, 2017. Disponível em: http://basenacionalcomum.mec.gov.br/a-base. Acesso em: 15 abr. 2018.

BRASIL. Ministério da Saúde. Secretaria de Atenção à Saúde. Departamento de Ações Programáticas Estratégicas. Diretrizes de atenção à pessoa com paralisia cerebral. Brasília: 2013.

BRASIL. Ministério da Educação. Secretaria de Educação Especial. Política Nacional de Educação Especial na Perspectiva da Educação Inclusiva. Brasília, DF. MEC- SEEESP, v. 4, n1, 2008. Disponível em: http://portal.mec.gov.br/index.php. Acesso em: 17 dez. 2018. 
BOOTH, T; AINSCOW, M. Index for Inclusion: A Guide to School Development Led by Inclusive Values. Bristol: CSIE, 2002.

CARVALHO, R. E. Educação Inclusiva: “com os pingos nos is”. Rosita Edler de Carvalho. 9. ed. Porto Alegre: Mediação, 2013. 176 p.

CRUZ, G.; GLAT, R. Educação Inclusiva: desafio, negligência e responsabilidade dos cursos de graduação. Educar em Revista, Curitiba, n. 52, p. 257-273, abr./jun. 2014. DOI: https://doi.org/10.1590/0104-4060.32950. Disponível em:

https://www.scielo.br/scielo.php?pid=S0104-

40602014000200015\&script=sci_abstract\&tlng=pt. Acesso em: 30 mar. 2019.

FACHINETTI, T.; GONCALVES, A.; LOURENCO, G. Processo de Construção de Recurso de Tecnologia Assistiva para Aluno com Paralisia Cerebral em Sala de Recursos

Multifuncionais. Rev. bras. educ. espec. v. 23, n. 4, p. 547-562. DOI:

https://doi.org/10.1590/s1413-65382317000400006. Disponível em:

https://www.scielo.br/scielo.php?pid=S1413-

$65382017000400547 \&$ script=sci_abstract\&tlng=pt. Acesso em: 15 maio 2019.

FRANCO, M. A. M; GUERRA, L. B. O ensino e a aprendizagem da criança com paralisia cerebral: ações pedagógicas possíveis no processo de alfabetização. Revista Educação

Especial, v. 28, n. 52, p. 311-32, 2015. DOI: https://doi.org/10.5902/1984686X14916. Disponível em: https://periodicos.ufsm.br/index.php/educacaoespecial/article/view/14916. Acesso em: 22 abr. 2019

GIL, A. C. Métodos e técnicas de pesquisa social. São Paulo: Atlas, 7. ed. 2019.

GLAT, R.; PLETSCH, M. D. (org.). Estratégias educacionais diferenciadas para alunos com necessidades especiais. Rio de Janeiro: EdUERJ, 2013. 200 p.

GLAT, R.; PLETSCH, M. D. Inclusão escolar de alunos com necessidades educacionais especiais. Rio de Janeiro: EdUERJ, 2011, 162 p.

GONZÁLES, Eugenio (org.). Necessidades educacionais específicas: intervenção psicoeducacional. Porto Alegre: Artmed, 2007.

GREGUOL, M.; GOBBI, E.; CARRARO, A. Formação de professores para a educação especial: uma discussão sobre os modelos brasileiro e italiano. Revista Brasileira de Educação Especial, Marília, v. 19, n. 3, p. 307-324, set. 2013. DOI: https://doi.org/10.1590/S1413-65382013000300002. Disponível em: https://www.scielo.br/scielo.php?pid=S141365382013000300002\&script=sci_abstract\&tlng=pt. Acesso em: 5 abr. 2019.

GUERRA, E. L. A. Manual de pesquisa qualitativa. Belo Horizonte: Grupo Ănima Educação, 2014.

HEREDERO, E. S. A escola inclusiva e estratégias para fazer frente a ela: as adaptações curriculares. Revista Acta Scientiarum Education, Maringá, v. 32, n. 2, p. 193-208, 2010. DOI: https://doi.org/10.4025/actascieduc.v32i2.9772. Disponível em: http://periodicos.uem.br/ojs/index.php/ActaSciEduc/article/view/9772. Acesso em: 10 abr. 2019. 
LEITE, J. M. R. S.; PRADO, G. F do. Paralisia Cerebral: aspectos fisioterapêuticos e clínicos. Revista Neurociências, São Paulo, v. 1, n. 12, p. 41-46, 2004. DOI:

https://doi.org/10.4181/RNC.2004.12.41. Disponível em:

https://periodicos.unifesp.br/index.php/neurociencias/article/view/8886. Acesso em: 22 abr. 2019.

MANTOAN, M. T. E. O desafio das diferenças nas escolas. Petrópolis: Vozes, 2008.

MANTOAN, M. T. E. Inclusão escolar: o que é? Por quê? Como fazer? São Paulo: Moderna, 2003. $51 \mathrm{p}$.

MARQUES, L. P.; OLIVEIRA L. A.; SANTOS, N. A. S. Integração de paralisados cerebrais: um estudo. Temas Sobre Desenvolvimento, v. 40, p. 16-23, 1998.

MARCHESI, Á. A prática das escolas inclusivas. In: COLL, C. et al. (org.).

Desenvolvimento psicológico e educação: necessidades educativas especiais e aprendizagem escolar. 2. ed. Porto Alegre: Artmed, 2004, p. 31-47.

MELO, F. R. L. V.; MARTINS, L. A. R. Acolhendo e atuando com alunos que apresentam paralisia cerebral na classe regular: a organização da escola. Revista Brasileira de Educação Especial, Marília, v. 13, n. 1, p. 111-130, 2007. DOI: http://dx.doi.org/10.1590/S141365382007000100008. Disponível em: https://www.scielo.br/scielo.php?pid=S141365382007000100008\&script=sci_abstract\&tlng=pt. Acesso em: 30 abr. 2019.

MENDES, E. Radicalization of the debate on school inclusion in Brazil. Revista Brasileira de Educação, v. 11, n. 33, p. 387-405, set./dez. 2006. DOI: https://doi.org/10.1590/S141324782006000300002. Disponível em:

https://www.scielo.br/scielo.php?script=sci_abstract\&pid=S1413-

24782006000300002\&lng=en\&nrm=iso. Acesso em: 20 abr. 2019.

MESQUITA, A. M. Currículo e Educação inclusiva: As Políticas Curriculares Nacionais. Espaço do Currículo, Paraíba, v.3, n. 1, p. 305-315, 2010.

OMOTE, S. Estigma no tempo da inclusão. Rev.Bras. Educ. Espec., Marília, v. 10, n. 3, p. 287-308, set./dez. 2004. Disponível em: http://www.scielo.br/scielo.php. Acesso em: 12 abr. 2019.

PACHECO, J. A. Notas sobre diversificação/ diferenciação curricular em Portugal. InterMeio: revista do Programa de Pós-Graduação em Educação, Campo Grande, v. 14, n. 28, p. 178-187, 2008. Disponível em:

https://periodicos.ufms.br/index.php/intm/article/view/2498. Acesso em: 16 abr. 2019.

PLETSCH, M. D.; SOUZA, F. F. DE; ORLEANS, L. F. A diferenciação curricular e o desenho universal na aprendizagem como princípios para a inclusão escolar. Revista educação e cultura contemporânea, Rio de Janeiro, v. 14, n. 35, p 264-261, 2017.

PELOSI, M. B. A. Inclusão e Tecnologia Assistiva. 2008. 303 f. Tese (Doutorado em Educação) - Programa de Pós-graduação em Educação da Faculdade de Educação, Universidade do Estado do Rio de Janeiro, Rio de Janeiro, 2008. 
RIBEIRO, M.L. S.; BAUMEL, R. C. R. Educação Especial: do querer ao fazer. São Paulo: Avercamp, 2003. 192 p.

RODRIGUES, D. Inclusão e educação: Doze olhares sobre a educação inclusiva. São Paulo: Summus, 2006. 318 p.

RODRIGUES, D. A educação e a diferença. In: D. Rodrigues (ed.), Educação e diferença: valores e práticas para uma educação inclusiva Porto: Porto Editora, 2001. p. 13-34.

ROCHA, A. N.; DELIBERATO, D. Tecnologia assistiva para a criança com paralisia cerebral na escola: identificação das necessidades. Rev. bras. educ. espec., Marília, v. 18, n. 1, p. 7192, 2012. DOI: https://doi.org/10.1590/S1413-65382012000100006. Disponível em: https://www.scielo.br/scielo.php?pid=S141365382012000100006\&script=sci_abstract\&tlng=pt. Acesso em: 18 abr. 2019.

ROLDÃO, M.C. Diferenciação curricular revisitada: conceito, discurso e práxis. Porto Editora, Porto/Portugal, 2003.

SACRISTÁN, J. G. O currículo: uma reflexão sobre a prática. 3. ed. Porto Alegre: ARTMED, 2000.

SANCHEZ, G. C.; ALMEIDA, R. C. G. O. GONÇALVES, A. G. Inclusão Escolar: os desafios de alunos com paralisia cerebral em seu processo de escolarização. REVELLI., v. 9, n. 2, p. 27-39, 2017. Disponível em:

https://www.revista.ueg.br/index.php/revelli/article/view/5897. Acesso em: 15 maio 2019.

SANTOS, V.; MENDES, E. G. Estud. Aval. Educ., São Paulo, v. 30, n. 74, p. 486-507, maio/ago. 2019.

SEVERINO, A.J. Metodologia do trabalho científico. 24. ed. São Paulo: Cortez, 2017.

SILVA, S. M.; SANTOS, R. R. N.; RIBAS, C. G. Inclusão de alunos com paralisia cerebral no ensino fundamental: contribuições da fisioterapia. Rev. bras. educ. espec., Marília, v. 17, n. 2, p. 263-286, Aug. 2011. DOI: https://doi.org/10.1590/S1413-65382011000200007.

Disponível em: https://www.scielo.br/scielo.php?pid=S1413-

65382011000200007\&script=sci_abstract\&tlng=pt. Acesso em: 06 jan de 2019.

TELES, R. O.; SANTOS, M. Tecnologias de Apoio. In: PEKER, Rukiye (coord.) Paralisia cerebral: manual de formação para pais e professores. Porto: Pozitif Matbaası, 2012.

VITALINO, C.R. VALENTE S.M.P. A formação de professores reflexivos como condição necessária para inclusão de alunos com necessidades educacionais especiais. In: VITALINO, C.R. (org.). Formação de professores para a inclusão de alunos com necessidades educacionais especiais. Londrina: EDUEL, 2010. p. 34-48.

Recebido em: 19/07/2019

Revisado em: 28/09/2020

Aprovado em: 30/09/2020

Publicado em: 15/03/2021

Educação: Teoria e Prática/ Rio Claro, SP/ v. 31, n.64/2021. eISSN 1981-8106 e03[2021] 